JWAM

14,1

Received 3 September 2020 Revised 27 October 2020 21 December 2020

18 January 2021

16 February 2021

Accepted 21 February 2021

\section{A qualitative study on the experiences and challenges of MBA students' engagement with a business research methods module}

\author{
Chinny Nzekwe-Excel ${ }^{\circledR}$ \\ University of Wolverhampton, Wolverhampton, UK
}

\begin{abstract}
Purpose - Undertaking research as part of a business degree qualification undoubtedly enables students to develop practical and life-long skills. Nevertheless, students seem to find it challenging undertaking a research project. This study set out to explore the experiences of a group of MBA students who recently undertook their business and management research projects as part of their MBA degree program.

Design/methodology/approach - The study was carried out in a UK higher education institution and is based on an MBA business and management research module. The purpose of the module is to enable learners to develop advanced-level independent research and critical problem-solving skills within a business context. The study adopted a qualitative approach to capture a broad mix of students' experiences and perceptions on the module. The sample includes previous MBA students on different cohorts and different nationalities.

Findings - Outcomes of the study show that though students are stretched in the business and management project process they develop a diversity of skills required in the workplace while conducting their projects. The study findings also show that the practical implications of the students' projects and progressive support from their project supervisors contribute to the successful completion of their projects and subsequent attainment of their MBA degree.

Originality/value - Outcomes of this study further reveal that undertaking business and management projects creates a rewarding learning experience for learners/students, develops confident graduates as well as enables effective applications of theory into practice.
\end{abstract}

Keywords Business research, Management, MBA, Research methods, Project

Paper type Research paper

\section{Introduction: study context and rationale}

Undertaking or conducting business and management research projects can be a daunting experience for students, probably because of the requirement to adopt an academic stance while undertaking the task/ project, which is intended to be practice-based. Students may demonstrate full engagement on the idea of undertaking a project or research; however they seem to disconnect from the requirement of doing so within the confines of academic research process. Thus, it can be a challenge for an academic, who is teaching a research methods module to guide/ encourage students to stay within the scope of an achievable research study (Lewthwaite and Nind, 2016). Over the past four decades, there is a reasonable number of studies on the challenges associated with teaching research methods as well as suggestions on how to encourage students to become more engaged and less anxious while undertaking their

(C) Chinny Nzekwe-Excel. Published in Journal of Work-Applied Management. Published by Emerald Publishing Limited. This article is published under the Creative Commons Attribution (CC BY 4.0) licence. Anyone may reproduce, distribute, translate and create derivative works of this article (for both commercial and non-commercial purposes), subject to full attribution to the original publication and authors. The full terms of this licence may be seen at http://creativecommons.org/licences/by/4.0/ legalcode 
research projects (Ransford and Butler, 1982; Zablotsky, 2001; Tashakkori and Teddlie, 2003; Ekmekci et al., 2012; Lewthwaite and Nind, 2016; Mullins, 2017). Carr (2014) collated and presented discussions from five studies on the challenges associated with teaching research methods in business and management to both undergraduate and MBA students. The challenges were around the epistemological assumptions and differing methodological conceptions of tutors, equipping staff/ tutors with statistical capabilities for quantitative research methodology and enabling students to develop the skills or aptitudes associated with the research process. The completion of students' projects can also be viewed in the context of collaborative or paired projects; an empirical study carried out by Ronnie (2017) shows high levels of positive outcomes. Amongst other factors, Ronnie's study reveals that early and ongoing conversations between the students, trust in each other's ability and self-reflection contribute to productive outcomes in the paired-project process.

The difficulty for students to engage with and to link the knowledge gained in the research methods teaching to the entirety of their higher education study is a recognisable challenge for the students (Winn, 1995; Chapdelaine and Chapman, 1999; Ekmekci et al., 2012). Winn (1995) suggests that live organisational issues or projects based on problems within a specific organisation can offer a unique opportunity toward mitigating such challenges. Similarly, Garnett et al. (2016) argue that there is the need for the projects to be grounded in real-time work-related issues. This may mean a review and subsequent redesign or reformation of the research methods module within the business and management discipline. Ekmekci et al. (2012) outline a number of reflective questions/recommendations and associated implications on how to enable students to apply the knowledge gained in their research methods course. A summary of the authors' recommendations show that tutors of the research methods course play a significant role in creating the right atmosphere that will enable students navigate their learning in a meaningful way.

With particular focus on qualitative research approach, Cassell (2018) discussed the challenges faced by over $200 \mathrm{MBA}$ students in conducting their business and management research. Cassell demonstrated the need for the students to develop the knowledge, skills and competences required for undertaking qualitative research, which can be used for effective management practice. While the focus of the business and management projects may not be categorically on aptitude or skills development, Toledano-O'Farrill (2017) argues that students are expected to develop workplace skills as a result of their involvement with the project activities. For example, qualitative research which involves a series of questioning between the researcher and the respondent as part of the data collection process for the research enables the researcher to develop skills such as critical thinking, reflective ability and communication skills (Wall et al., 2017a, b).

Evidence shows that MBA students enrol on their MBA course with minimal work experience and critical thinking ability (Schaupp and Vitullo, 2019), which highlights the need for research methods to be taught in such a way that students are enabled to "build-up" the required knowledge and competences (Galliers and Huang, 2012). Similarly, Llamas and Boza (2011) argue that research methods by definition should be applicable to a specific discipline (or practice). In a similar line of argument, Beardwell and Claydon (2007, cited in Rowe et al., 2017) echo that employers prefer graduates who have the ability to reflect and synthesise opinions through critical thinking. The challenges of undertaking their business and management research projects raise the questions: how MBA students apply critical thinking to practical problems, how to keep them engaged throughout the research process and essentially how to enable them to confidently develop or enhance a wide range of personal and professional skills, which are a necessity in today's workplace.

Therefore, the aim of this study is to explore the experiences of a group of MBA students who recently undertook their business research module and completed their business and management research project as part of their MBA degree program.
Experiences and challenges of MBA students 
JWAM

14,1

\section{Research module design}

This study explores student experiences in completing a business and management research module and in carrying out a business and management research project. One of the key requirements of the research module is for students to define their project topics themselves with assistance from their project supervisors. The module is developed to include interactive teaching components, action-learning sets (ALS), which are designed to be student-led and tutor-facilitated and individual (and in some cases, group) supervision. The module design incorporates the active-blended learning concepts, including a combination of face-to-face and virtual/ online sessions.

The interactive teaching components are delivered through a number of focused workshops. Six key focus areas of the interactive workshops are:

(1) Planning the business and management research

(2) Conducting and writing up the literature review

(3) Deciding on the right methodological approaches; Research Governance and Ethics

(4) Collecting and gathering data

(5) Analysing and interpreting data

(6) Dissemination and presentation: Write-up of the project report.

The ALS are designed to help consolidate the research project process, enable students to frame their research ideology and to make more tailored decisions for their individual business and management research. At this stage of the process, students may become anxious initially; however with support and guidance from their project supervisors, they should be able to channel their energy and anxiety toward making better informed decisions and choices for their business and management research. It is also during the ALS classes that students begin to develop the confidence to undertake their individual business and management research projects; the ALS classes provide an environment for learners to share their research experiences, express their challenges and suggest strategies with tailored support or advice from their project supervisors.

\section{Methodology}

\section{Paradigm and research stance}

An interpretivist paradigm was adopted for this study; this enabled gaining an understanding of the research focus through subjective relationship with the participants (Manroop, 2017). Interpretivism places focus on the perceptions, interpretations and experiences of individuals (Cohen et al., 2010; Fisher, 2010). Therefore, interpretivism was assumed for this study with the intention to individually question the study participants and to gain an understanding of their experiences from undertaking their business and management research projects. Consequently, a qualitative methodology was employed, which created a platform to generate in-depth personal information on the subject under study. This approach was considered more appropriate considering the intention to explore the views and experiences of a diversity of postgraduate students who have recently undertaken the assessed business and management research module. Thus, this methodology enabled the investigation of student learning experience in the area of undertaking business and management research and thorough evaluation of the perceptions of different categories of students.

\section{Sample}

This study recruited participants from a United Kingdom (UK) public university with campuses in the UK and two partner institutions in Vietnam. Precisely, the concept of 
purposeful sampling was used, which means that a selection of students enrolled on the business and management research module (under discussion) was recruited as participants for the study because they could purposefully inform an understanding of the aim of the study (Creswell, 2013). A total of four cohorts from two academic years (2016/17 and 2017/18) were considered for this study, which had a total of 54 students enrolled on the module. 33 were contacted, and 13 agreed to be part of the study. However, only 11 attended the interview sessions, which resulted in a small sample. Nonetheless, there is evidence to suggest that the sample size of 11 for a qualitative study can be considered as being suitable. Morse (1994, cited in Guest et al., 2006) recommended a minimum of six participants while Dukes (1984) and Reimen (1986) (both cited in Creswell, 2013) recommended a sample size of 3-10. As perceived by 14 qualitative research experts collated by Baker et al. (2012), the sample size for a qualitative study varies and will depend on the number of participants who are sufficient to provide evidence on the issue under discussion; some of the experts argue that one interview is sometimes sufficient (p. 16; 24), while some other experts suggest a minimum sample size of 12 (p. 11; 19).

This study's population (54) comprised students who received the same teaching sessions from the same research module. It is aimed at exploring the students' experiences on undertaking the business research module and completing their research project; therefore, effort was made to draw rich, detailed responses and insights from the 11 participants. Subsequently, critical evaluations of the collected data were carried out. Thus, data saturation was considered and achieved through the sampling process, data collection strategy, the study timeframe and data analysis. The 11 participants who contributed to the study are recent MBA graduates of the UK Higher Education Institution under study, who achieved varied grade categories in the business and management research module assessment. All the participants were on full-time MBA programme and eight were in some form of employment during their MBA study. Details of the participants are shown in Table 1 . The 11 participants comprised five participants who had the module taught and delivered in the UK and six participants who had the module taught and delivered outside the UK (in Vietnam).

\begin{tabular}{|c|c|c|c|c|c|}
\hline $\begin{array}{l}\text { Designation/ } \\
\text { Identifier No }\end{array}$ & Employment & Gender & $\begin{array}{l}\text { Academic year of } \\
\text { undertaking the business } \\
\text { research module }\end{array}$ & $\begin{array}{l}\text { Place of } \\
\text { module } \\
\text { delivery }\end{array}$ & $\begin{array}{l}\text { Duration of } \\
\text { interview }\end{array}$ \\
\hline VNT-HMC1 & Full time & Female & $2016 / 17$ & Vietnam & $43 \mathrm{~min}$ \\
\hline VNU-HMC2 & Full time & Female & $2016 / 17$ & Vietnam & $37 \min$ \\
\hline VNJ-HMC3 & Full time & Male & $2016 / 17$ & Vietnam & $37 \mathrm{~min}$ \\
\hline VNL-Hanoi1 & Full time & Female & $2017 / 18$ & Vietnam & $34 \mathrm{~min}$ \\
\hline VNT-Hanoi2 & Full time & Male & $2017 / 18$ & Vietnam & $43 \mathrm{~min}$ \\
\hline VNK-Hanoi3 & Full time & Male & $2017 / 18$ & Vietnam & $40 \mathrm{~min}$ \\
\hline INTC-UK1 & Part time & Female & 2016/17 & $\begin{array}{l}\text { United } \\
\text { Kingdom }\end{array}$ & $39 \mathrm{~min}$ \\
\hline INTC-UK2 & No & Male & 2016/17 & $\begin{array}{l}\text { United } \\
\text { Kingdom }\end{array}$ & $36 \min$ \\
\hline INTP-UK3 & Part time & Female & $2017 / 18$ & $\begin{array}{l}\text { United } \\
\text { Kingdom }\end{array}$ & $42 \mathrm{~min}$ \\
\hline INTP-UK4 & No & Male & $2017 / 18$ & $\begin{array}{l}\text { United } \\
\text { Kingdom }\end{array}$ & $39 \mathrm{~min}$ \\
\hline INTH-UK5 & No & Female & $2017 / 18$ & $\begin{array}{l}\text { United } \\
\text { Kingdom }\end{array}$ & $38 \mathrm{~min}$ \\
\hline
\end{tabular}

Experiences and challenges of MBA students 
JWAM

14,1

\section{Approach and data collection procedure}

The interview technique was the primary data collection tool that was adopted to capture the students' experiences in undertaking their business and management research projects as well as their perceptions on the research module under study. All the interview sessions were carried out between March and June 2019, when the students/participants were not under any form of academic pressure in terms of exams or pending assignments/resits. In addition, all the interview sessions were carried out in consideration of the participants' availability and convenience. Prior to the data collection, appropriate ethical approval was adhered to, which included obtaining each participant's signed consent before the interview sessions. A participant information sheet, which outlined the purpose of the study and explained the conditions for participation was given to each interview participant before conducting the interviews. Subsequently, voluntary participation, issues of strict confidentiality and participants' anonymity were established. Prior to the data collection, an individual email containing the consent form was sent to each participant to sign their consent to participate in the interview. Each of the 11 participants had their one interview session organised and carried out in a formal fashion, and each interview session lasted approximately $40 \mathrm{~min}$ (see Table 1). During the interview sessions, simpler opening questions were used to ease the interviewees, thereby ensuring that any form of tension or anxiety was eliminated or reduced (Nzekwe-Excel, 2012). Similarly, pertinent closing questions were used to enable the interviewees make concluding remarks and/or additional comments to their earlier responses. Effort was made to keep the participants within the focus of the study by highlighting the purpose of the study as well as asking additional questions for clarity. In addition, each interview was audio-recorded and fully transcribed.

The interview questions, which were put together in view of the aforementioned aim of the study, were broadly focused on gaining insights on the students' experiences from undertaking their business and management research projects and their perceptions on the business and management research module. All 11 interviewees were presented with the same interview questions, which focused on the following:

(1) Students/ participants' expectations from the research module before the teaching/ delivery

(2) Students/ participants' expectations from the research module during the teaching/ delivery

(3) Students/ participants' positive experiences while undertaking their business and management research projects

(4) Students/ participants' challenging experiences while undertaking their business and management research projects and how these were managed

(5) Students/ participants' perceptions on whether their expectations were met and the benefits of the business and management research module

(6) The participants' recommendations in the review/ redesign of the business and management research module

\section{Analytical procedure}

The concept of thematic analysis was used in analysing and interpreting the data. Precisely, thematic analysis was used for identifying themes and patterns of behaviour or meanings in the interview/ qualitative dataset. The themes are developed by placing the initial coding of the data in such a way that they can be moved around to form connections with data that has similar coding (Howitt and Cramer, 2008). Themes are defined as "conversation topics, 
vocabulary, recurring activities, meanings, feelings, and proverbs" (Taylor and Bogdan, 1984, p. 131, cited in Aronson, 1994). For the purpose of this study, the themes are phrases or comments, also known as the participants' responses. Therefore, thematic analysis was employed because of its flexibility in identifying participants' experiences, views and behaviours, which seeks to understand what participants' think, feel and do (Clarke and Braun, 2017). The six phases of implementing thematic analysis as suggested by Braun and Clarke (2006) were considered in analysing the collected/ interview data of this study. The six phases include: familiarisation of the data, generation of initial codes, searching for themes, reviewing the themes, defining and naming the themes and then producing the report.

Sufficient time was dedicated toward transcribing, reviewing the data as well as making initial notes. The NVIVO qualitative data analysis software was employed for the initial coding process of the data, which subsequently helped in searching for/ identifying themes. NVIVO provided a platform for grouping the data in different ways using folders, sets and cases for coding, easy access and retrieval of the data (Wiltshier, 2011). As an approach to data analyses, the identified themes (generated data) were reviewed, and named by managing, classifying, and categorising the data using a process of reduction and coding technique (Nzekwe-Excel, 2012). Subsequently, meaningful textual segments were derived based on similar and/or dissimilar viewpoints of the study's participants (Nzekwe-Excel, 2012).

\section{Data analyses and findings}

The study findings are focused on factors that underpin students' knowledge of, proficiency in and application of a range of methodologies in a business and management research project. Responses from the interview sessions were broadly coded "PEAR" (Figure 1). More precisely, defining and analysing the themes from the generated data, in consideration of the aforementioned interview questions, were done in such a way that:

(1) The first two interview questions were aimed at exploring the students' preparedness and engagement prior to and during the delivery of the business and management research module. Responses from these questions were grouped under the themedcategory labelled "Preparedness". The theme "Preparedness" was used because it reflects how students were prepared for the business and management research module, including their expectations and learning needs.

(2) The third and fourth questions were aimed at exploring the students' critical thinking ability and their engagement with the module. Responses from these questions were grouped under the themed-category labelled "Engagement". The theme "Engagement" was used because it reflects the students' ongoing interest in the module including challenges and their learning development from the module.

(3) The fifth question was aimed at exploring the students' ability to manage the entire research process from question formulation through to analysis and interpretation of

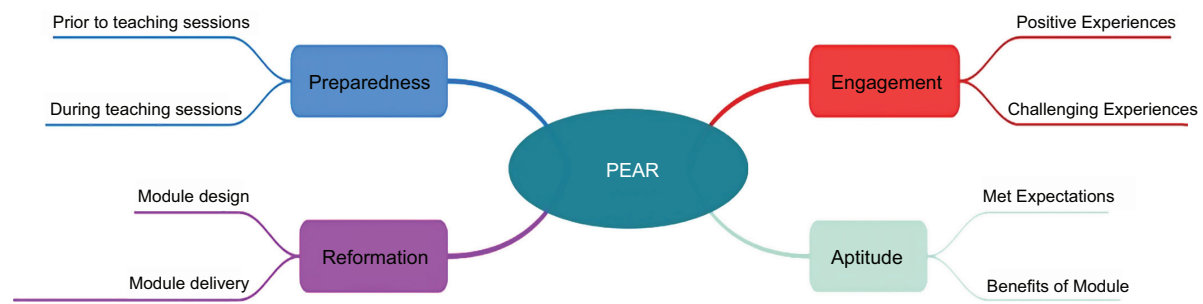

Experiences and challenges of MBA students 
JWAM

14,1

\section{2}

Figure 2.

Interview themes: expectations and learning needs from business and management research results. Responses from this question were grouped under the themed-category labelled "Aptitude". The theme "Aptitude" was used because it reflects the students' personal and research skills development including their met expectations and learning needs.

(4) Finally, participants were given the opportunity to make additional comments regarding the progressive review and delivery of the module through the sixth/ final question. Responses from this question were grouped under the themed-category labelled "Reformation". The theme "Reformation" was used because it reflects the students' suggestions on how the business and management research Module can be further enhanced in its design and delivery.

It is important to note that the terms "Preparedness", "Engagement", "Aptitude" and "Reformation" were put together in view of the aim of this study as well as to categorise the participants' responses accordingly.

\section{Preparedness of the students}

The study identified a number of themes in an evaluation of students' expectations before and during the teaching sessions for the business and management research module. The students' "prior" expectations were generally focussed on their desire to gain or expand their knowledge on business and management research processes and on what to do to succeed in the module assessment. A careful review of the students' expectations "during" the teaching sessions show focused research needs as shown in Figure 2.

\section{Engagement of the students}

The students' engagement throughout the duration of the module delivery and the conduct of their individual projects were analysed based on their perceptions on what they enjoyed, the challenges they encountered and their coping mechanisms. Most of the positive experiences shown by the interviewees' supportive comments express the learning or skills gained in conducting their business and management projects and confidence developed in the area of business and management research strategies (Figure 3). With respect to the challenges that the students encountered while conducting their projects, references were made to a number of factors associated with different stages of their projects, the online mode of module delivery and personal issues such as managing and combining full-time study and full-time employment.

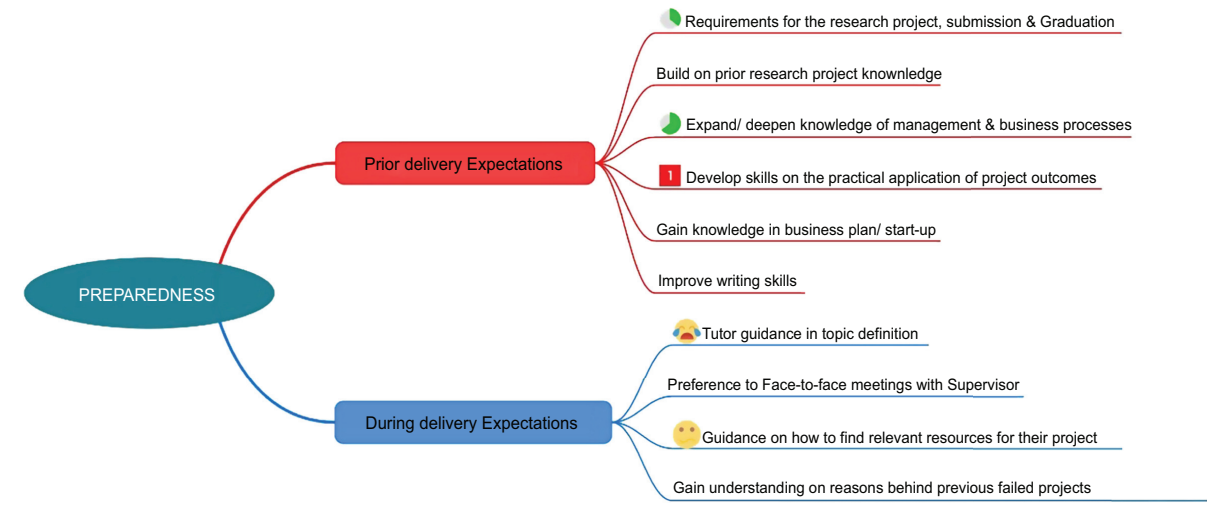




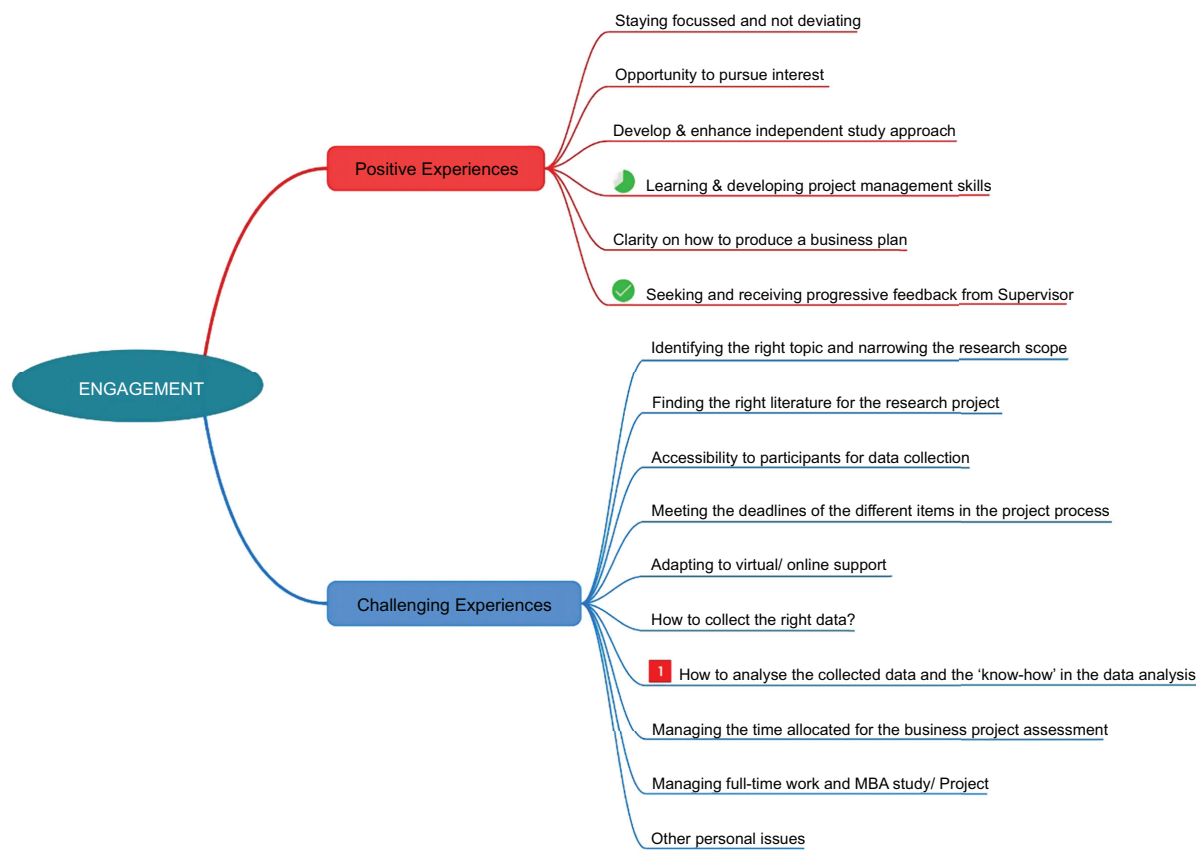

\section{Experiences and challenges of MBA students}

53

\section{Aptitude of the students}

In an attempt to explore the students' ability to manage their entire research process and demonstrate a consistent focus on their arguments, this study sought to find out the participants' perceptions on whether their "prior" and "during" module expectations were met as well as the participants' views on the benefits of the module to them on a personal basis. As illustrated in Figure 4, the findings show strong positive affirmations from the

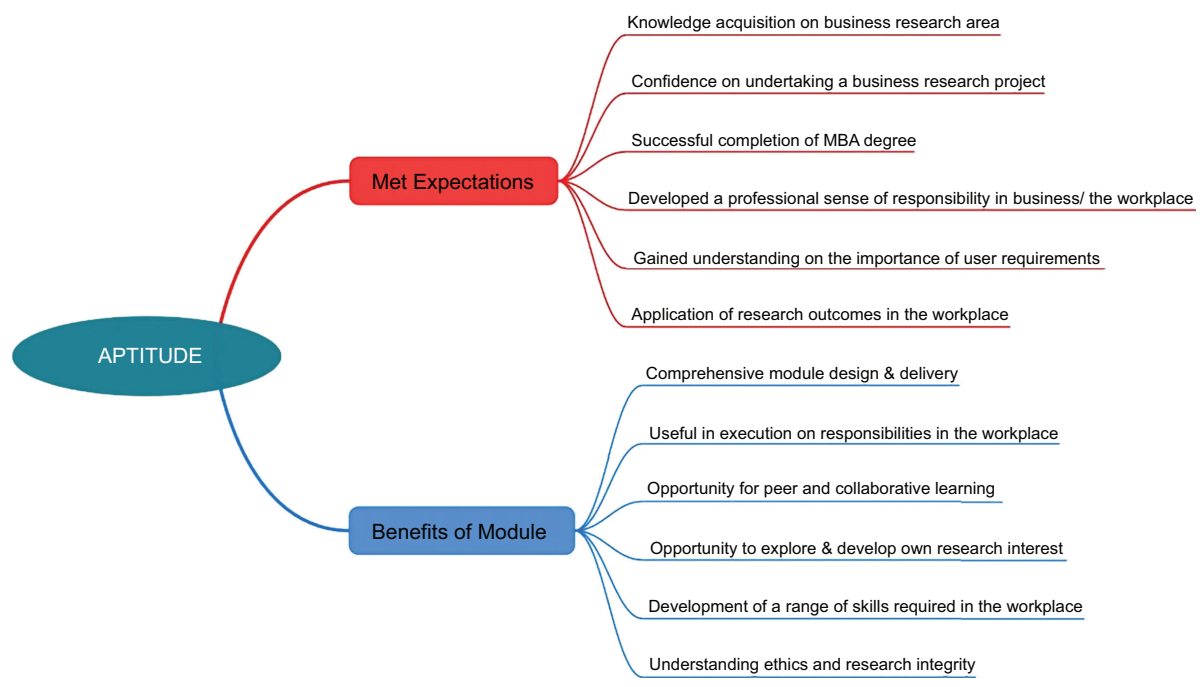

Figure 4.

Interview themes: Benefits associated with business and management research

Interview themes: Learning and skills gained in business and management research 
JWAM

14,1

\section{4}

participants. There are also demonstrations of understanding on the systematic stages of the research process.

\section{Reformation of the module}

As a way forward toward upgrading the business and management research module, the study drew insights from the participants. The findings, as shown in Figure 5, uncover varied viewpoints, mostly around the timing allocated to the module delivery and quantitative/ statistical support sessions. Interestingly, some of the participants noted that they simply like the module design/ delivery as it is and do not think a redesign is necessary.

\section{Evaluation of findings and discussions}

This study presents verbatim quotes of the interview participants (in italics) as a way to reinforce the study findings. The participants' identifier numbers shown in Table 1 are written next to the quotes.

\section{Business and management research expectations and learning needs}

Being the final module that the students are expected to complete and pass before being considered for their MBA degree qualification, it is no surprise that some of the students' expectations prior to undertaking their business and management research projects were focused on the successful completion and submission of the project assessment. This is shown by comments from two of the interviewees: "I had expectation on graduation" (INTCUK2); "I had a knowledge shortage. I wanted to know what is expected...in submission" (INTH-UK5).

Postgraduate students may lack sufficient knowledge to critically engage with research and the different methodological approaches (Savage and Burrows, 2007), so the expectation on "gaining knowledge" as can also be seen in the participants' comments is not out-of-place:

"we were not sure how to do research. . .to have some knowledge transfer" (INTH-UK5).

"I had little knowledge. . .Um, the advancement of knowledge especially on facial products. . .More socialisation with people. . . I became a specialist” (INTC-UK2).

"It has. . .broadened my knowledge in the area that I researched on... . it made me have a more critical thinking approach... making sure you are exactly on point in asking the right questions" (INTH-UK5).

Eight of the 11 interview participants were in some form of employment during their MBA study; therefore, the application of the knowledge gained is even more relevant, particularly for working students or students who are in some form of employment as well as for students

Figure 5.

Interview themes: review of business and management research module

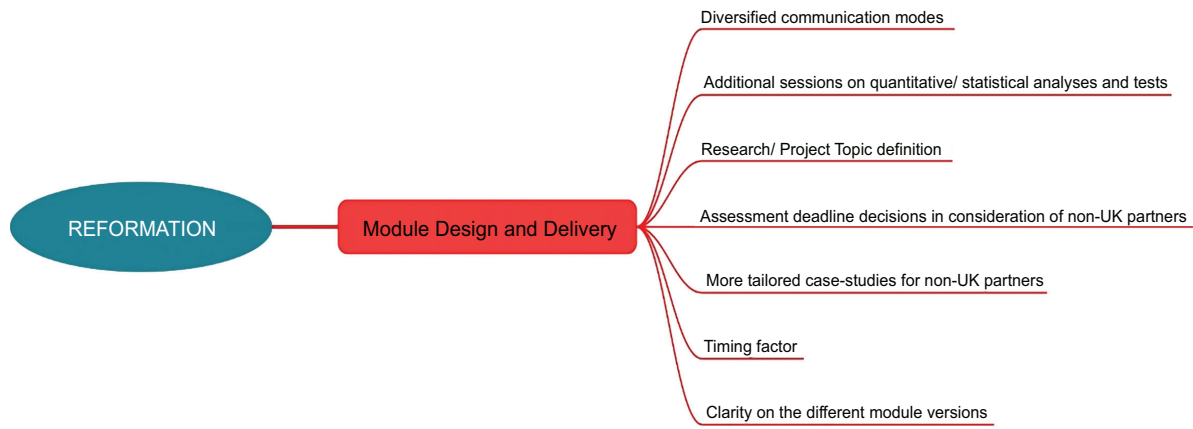


with no work experience. An evaluation of the participants' employment status shows that all the participants who were in full-time employment had prior expectations focused on the practical relevance of the module in organisational or workplace context:

"Applying the knowledge that is being learned to. . . specific business projects" (VNT-Hanoi2)

"I wanted to explore. . .business research process to apply in practical. .." (VNL-Hanoi2)

"Mostly, I expect. . .to get the implication and recommendation to handle the situation we are facing (in the organisation); gaining knowledge to apply to my current organisation' I try to check my topic with my organisation. . . to deliver the project" (VNJ-HMC3).

"I had an expectation that the module will provide me a way we can know to start a business plan" (VNU-HMC2).

"I wanted to know more information on the business market" (VNT-HMC1).

In addition, one of two of the participants in part-time employment at the time of the module delivery also expected to acquire knowledge on business concepts in view of their career aspirations: "I expected this module will give...an opportunity to study new knowledge. . . for . . future when I want to start my own business..." (INTP-UK3).

Though there is some overlap in the participants' "prior" and "during" module delivery expectations, some issues appear to have arisen once the module was in process such as definition of research topic, choosing the right approach and finding the appropriate resources for the project (Figure 2). Some of the participants' comments in these regards include:

"I had questions such as "what am I gonna do for my dissertation? "will I find my topic?" (INTC-UK1)

"The subject of the research topic: because the topic I chose has also been chosen by another. So the difficulty is in decision making for the topic" (INTC-UK2).

"how to define a topic was confusing. . . but by end of the teaching week, I had idea on what to do my research on" (INTH-UK5).

"Therefore, what I expect was finding a suitable method for the research topic. . .to proceed" (VNKHanoi3).

Unsurprisingly, some of the participants' comments on the research process and expectations uncover challenging/ negative experiences to some degree:

"I expected that. . .my research is easy to find and not much difficult to understand but my thinking was wrong; some were easy to understand but some were difficult to understand" (INTP-UK3).

"Struggled with which methodology to go by... what should I use to support my research? These took a lot of time" (INTH-UK5).

". . . due to my chosen topic, I had to travel back home to interview the participants. There were times when I couldn't find the appropriate literature to support my research" (INTP-UK4).

One of the participants noted that their met expectations were more in theory than in practice, which suggests a drawback: "Actually for me, the expectations were met more in theory than in practical" (VNU-HMC2). The same participant suggested that the teaching sessions should be more tailored to their own environment: ". . .to be met in practice, it can be based in more research in Vietnam market” (VNU-HMC2).

Business and management research learning experience and skills gained

The themes identified for the "Aptitude" category (Figure 4) demonstrates realisation of the participants' preparedness for the module, in terms of having their expectations for the
Experiences and challenges of MBA students 
JWAM

14,1

business and management research module met, attainment of knowledge on basic concepts of the business and management research processes, development of academic and professional skills and an understanding on the relevance and practicality associated with their business and management research projects. Examples of specific comments that reflect these include:

"I also understood about the changes that I could suggest making it easier for women to work in bank" (INTP-UK4).

"When I finish and submit, I think I made a difference for myself" (VNJ-HMC3)

"The skills I developed doing this module are my study skills, research skills, analysing skills" (INTC-UK1).

"Absolutely. . .bring me many skills like developing independent working skills, problem solving skills, management skills, decision-making skills, market research, data analysis” (VNT-Hanoi2).

"Yes, the project provided insights for my organisation, and it meet the expectation, and it's good timing" (VNJ-HMC3).

"I think this module is very valuable for me so I know how to conduct a research and I learn about time management and I learn about how to conduct the survey, and know about the research questions" (VNJ-HMC3)

The above participants' positive comments suggest that the goal of the module to enable learners to be equipped with or develop the skills to undertake research on a high level (Kilburn et al., 2014), and of course on a practical basis in the workplace is a welcomed approach.

Nonetheless, the findings reveal some negative experiences from the participants:

"The other challenge I faced was the fact that we had to do online classes. . . in my view if we were present physically in the class with teachers, it would have been better. (INTP-UK4).

"However it is also hard to catch up...ideas because the other students showed up without preparation. In addition, we. . work full time and study therefore hard to follow the deadlines while lack of statistics and software experiences" (VNL-Hanoil).

One of the participants commented on the opportunity for students to interact and share ideas in the teaching and learning environment: "It's also interesting to listen to the others' ideas to see how they implement the research on different industries and various cases" (VNL-Hanoi1). These insights indicate the strength of action learning sets and the workshop teaching method. Workshops enable dialogue and constructive interactions between learners and tutors (Nzekwe-Excel, 2014). In their discussion on the role of action learning concept/ approach in executive management program, Johnson and Spicer (2006) and Kelliher and Byrne (2018) assert that the approach fosters learning, effective interactions, progress and knowledge transfer. In addition, Ronnie (2017) elucidates that there is an opportunity for collaborative dialogue and an atmosphere for students to build on each other's ideas: "I remember, Iidentified the wrong topic and my scope was very big and I get support from my classmates" (VNJ-HMC3).

The findings and analysis further show that the students' engagement was sustained through the continuous support from their project supervisors shown by $100 \%$ consensus on this; some of the supporting evidence are:

"readily available tutor-support'; "quick response from the project supervisor, which helped speed the project process" (INTC-UK1).

“...were my supervisor kept on providing me feedback whenever, I mailed her any of my work completed" (INTP-UK4). 
"I'm really thankful of the conversations I received from my tutors" (INTH-UK5).

"Um, I think for me, it's very helpful and Project Supervisor's guidance is helpful” (VNJ-HMC3).

"the Project Supervisor teach on how to take care of each work, how to use exact words for..." (VNU-HMC2).

A key component in undertaking business and management research projects is adherence to appropriate ethical procedures; the ethical procedure is expected to demonstrate research governance and integrity, particularly in the design of the data collection procedure/ tool. Interestingly, one of the interviewees highlighted the learning she gained while undergoing the rigorous ethical approval process: "For me, actually I learnt from. . .first of all is Ethics Form...teach on how to take care of each work, how to use exact words for each person. . .make the questionnaire for the customer service. . . (VNU-HMC2).

A careful review of the reflective comments from two of the participants who achieved a fail grade still demonstrate an understanding on the principles of undertaking research, an application of knowledge gained and thus show that learning did occur. According to Doyle and Zakrajsek (2013 cited in Mullins, 2017), true learning occurs when information can be used:

"For me, actually I learnt ... first of all. .." (VNU-HMC2).

"I did not fully understand the principles of qualitative research, so I encountered many difficulties in the process of analysing.... Although I failed to do a quality research...the study helped me understand important principles such as collecting and analysing data accurately. Besides, I also get better understood the importance of determining goals. .., I also realized that not spending enough time to review theory and doing research is a major cause of this failure" (VNK-Hanoi3).

"For me I can make the questionnaire for. . .industry so we can control the quality of the service" (VNU-HMC2).

"However, what I have not really understood after the course is that I still have not fully understood how to effectively apply qualitative and quantitative analysis methods to other kinds of research" (VNK-Hanoi3).

Notwithstanding the concern and possible anxiety that the students experienced in the process of deciding on a topic for their business and management research, half of the participants commented that they liked the privilege of deciding on the project topic themselves. This can be seen in Ekmekci et al. (2012)'s study, where the authors point out that having students develop their project titles help to consolidate their review of literature and engagement with the research methods course. There were a few contrary opinions:

"I prefer that I will identify the topic by myself and if I think it's too big, I will get guidance from my project supervisor and I will change by myself because actually I learn by myself a lot" (VNJ-HMC3).

"Providing the topics may be a good for those not knowing what they gonna do or kind of lost, that is students who are unsure of their career prospects. On the contrary, doing so, will limit students' ability to think outside the box, limit their creativity and initiation” (INTC-UK1).

"like to decide the title but at the same time have the tutor support on the recommendation on the topic, which my tutors did" (INTH-UK5).

"Well it depends on the students. Personally, I do recommend you choose me a topic because to be honest I don't know what to choose as it's the first time of the research. I think it will facilitate the students if you provide the students the topic to choose. It may also block the ability of the students to think outside the box" (INTC-UK2).
Experiences and challenges of MBA students 
JWAM

14,1

These show that the business and management research module provides a unique opportunity for learners to explore or examine an area of interest on a specific subject within the business and management discipline.

An exploration of the participants' comments on the "timing" theme broadly reflect management of the students' time throughout their business and management research process: ". . . challenge of time management" (VNJ-HMC3); "A challenge I had was to follow on the schedule...because we had to share our time. . and working (VNT-HMC1)"; "Challenge I had was managing my time with respect to personal job commitments and attend the sessions as well, and commuting. . from. . . most times made the project challenging" (INTC-UK1). These unimpressive comments also suggest a personal act of discipline, commitment and responsibility from the students are required to successfully complete their business and management research. A slightly different comment on "timing": "Deadlines should note the holiday leave of professors as we have different new year holiday. . we don't have holidays for Christmas and New Year" (VNL-Hanoi1) still highlights the need for students to develop the habit of good time management practice. The module assessment deadline is set well in advance before the module delivery and the students are made aware of the deadline in the first teaching session. In addition, the students are sent deadline reminders throughout the duration of the module/ their business and management research.

Another area where the students appeared to find challenging is in their data analyses and the technicality of their chosen data analysis software (SPSS): "I wish that we could have a workshop for 1 hour or...n the classroom. . . teach us a bit more about SPSS first because for some of us, that's the first time they hear about SPSS" (VNU-HMC2). It is not surprising that this issue was raised again when asked on their views for recommendations on the review/ redesign of the module. Similarly, some of the themes identified as the participants' challenging experiences (Figure 3) were identified as themes for the reformation of the module (Figure 5).

\section{Future direction for the business and management research module}

Reflecting on the participants' recommendations for the business and management research module (Figure 5) and in consideration of the main highlights from the study findings (discussed above), the review of the module will be addressed from two perspectives: module design and module delivery. It is important to note that the themes shown in Figure 5 have been defined in such a way that they are strategies aimed to be implemented in the review of the module's content and activities.

At present, qualitative and quantitative data analyses taught sessions are embedded in the module design, with an inclusion of independent/ additional support sessions available to students to take advantage of from the university learning development/ statistics team. However, the participants' responses or concerns around quantitative evaluations, including software usage ("Should have a separate session to train software/ statistics" (VNL-Hanoil); "My challenge is knowledge about the statistics I used in my research because Inever known and done it before" (INTP-UK3); "I think that choosing the right form of analysis (qualitative or quantitative) for different research objects is very important. . the module should focus more deeply on...analysing information with specific examples" (VNK-Hanoi3)) suggest that students are not taking advantage of the additional support sessions tailored toward qualitative and quantitative/ statistical evaluations. Though research shows that it is not unusual for students to be anxious or concerned toward statistical evaluations (Baglin et al., 2017), it may be a step in the right direction to "formally" embed the additional support sessions on quantitative/ statistical evaluations and qualitative analysis in the module design and delivery to bridge this knowledge gap. The contents of the additional support sessions will need to be modified or updated accordingly for each cohort considering that students' 
research topics vary. Some degree of competence in statistical evaluations is expected from today's graduates in the workplace as shown in the outcomes from Harraway and Barker (2005) study; so the formalised additional support or specialised data analyses sessions may be one way to develop and harness this skill in students as they undertake their business and management research projects.

With respect to decision-making for the research topic, a possible way forward is to have two options including students deciding on their project topics themselves and students' choosing a topic from a list made available to the students. Making a list of project topics available could help trigger possible areas that the students may want to focus their research on. This may consequently minimise unnecessary anxiety, enable effective time management, foster/ boost the research profile of the institution as the predefined research topics will be put together in consideration of the institution's current research areas/ foci. In addition, aspirational research areas could be developed or expanded on through the predefined research topics; the list of topics could be put together to embrace a wider perspective and in consideration of locations where the module is taught or delivered, which is in view of one of the non-UK participants' comments: "If possible, ... add more casestudy in the module design and delivery; I think the case study should be ... focussed in Vietnam (VNT-HMC1)". Whether students define their project topic themselves or make a choice for a project topic based on a list of available topics, it is important that students are guided and supported on how to decide/define their project topic with careful consideration of what they have a passion for. In his discussion on a six-stage process for choosing a project topic, Fisher (2010) identifies interest as the first stage or fundamental requirement of the topic definition.

The theme "Diversified communication modes" refers to how information is communicated to (and with) the students enrolled on the module. An unsurprising comment from one of the participants "Use social media i.e. Whatsapp Facebook, Instagram and email students directly instead of expecting them to always check the Learning_Environment [1] site" (INTC-UK2) demonstrates the drive for IT embrace in today's society. With a module that already has the concepts of active-blended learning in its design, extending its communication platforms as a means to facilitate student engagement and success should be a straightforward process.

\section{Concluding remarks and further research}

The critical evaluations of the findings from the qualitative data discussed in the preceding sections of this paper show the relevance, benefits and challenges associated with the business and management research module in the personal and professional development of learners. This study contributes to knowledge and practice on teaching research methods and supporting students while they undertake their business and management projects as follows: the study findings provide useful insights on MBA students' preparedness for undertaking business and management research projects, the students' development of a range of personal, practical and research skills and triggers for enabling the students' engagement throughout the research process. Furthermore, outcomes of this study suggest that where the challenges associated with undertaking business and management research projects are adequately channelled toward developing practical skills required in the workplace through progressive support from the academic project supervisors, it will contribute toward creating a rewarding learning experience for learners as well as enabling effective applications of theory into practice.

While transcribing the data and carefully reviewing the participants' responses, and making initial notes, it was observed that factors such as gender, academic year when the module was delivered and place of module delivery did not uncover any obvious disparity in the participants' responses to the interview questions. Nevertheless, there is still an
Experiences and challenges of MBA students 
JWAM

14,1

opportunity for further research on the possible effects of these factors on the students' academic performance/ grade achieved.

\section{ORCID iDs}

Chinny Nzekwe-Excel Dhttp://orcid.org/0000-0002-5671-0197

\section{Note}

1. Learning_Environment $=$ This is the acronym for the virtual learning environment of the higher education institution under study.

\section{References}

Aronson, J. (1994), “A pragmatic view of thematic analysis”, The Qualitative Report, Vol. 2 No. 1, [online], available at: http://www.nova.edu/ssss/QR/BackIssues/QR2-1/aronson.html (accessed 21 June 2019).

Baglin, J., Hart, C. and Stow, S. (2017), “The statistical knowledge gap in higher degree by research students: the supervisors' perspective", Higher Education Research and Development, Vol. 36 No. 5, pp. 875-889.

Baker, S.E., Edwards, R. and Doidge, M. (2012), "How many qualitative interviews is enough? Expert voices and early career reflections on sampling and cases in qualitative research", National Centre for Research Methods Review Paper, [online], available at: how_many_interviews. pdf(ncrm.ac.uk) (accessed 16 January 2021)..

Beardwell, J. and Claydon, T. (Eds) (2007), Human Resource Management: A Contemporary Approach, Pearson Education, London.

Braun, V. and Clarke, V. (2006), "Using thematic analysis in psychology", Qualitative Research in Psychology, Vol. 3 No. 2, pp. 77-101.

Carr, J (2014), Teaching research methods in business and management, Workshop funded as part of one of HEA Social Science's strategic priorities 2013 - 14, [online], available at: https://www. heacademy.ac.uk/teaching-research-methods-business-and-management (accessed 28 June 2019).

Cassell, C. (2018), "Pushed beyond my comfort zone: MBA student experiences of conducting qualitative research", The Academy of Management Learning and Education, Vol. 17 No. 2, pp. 119-136.

Chapdelaine, A. and Chapman, B.L. (1999), "Using community-based research projects to teach research methods", Teaching of Psychology, Vol. 26 No. 2, pp. 101-105.

Clarke, V. and Braun, V. (2017), "Thematic analysis: commentary”, The Journal of Positive Psychology, Vol. 12 No. 3, pp. 297-298.

Cohen, L., Manion, L. and Morrison, K. (2010), Research Methods in Education, 6th ed., Routledge, London.

Creswell, J. (2013), Qualitative Inquiry and Research Design: Choosing Among Five Traditions, 3rd ed., Sage, London.

Doyle, T. and Zakrajsek (2013), The New Science of Learning: How to Learn in Harmony with Your Brain, Stylus Publishing, Sterling, VA.

Dukes, S. (1984), "Phenomenological methodology in the human sciences", Journal of Religion and Health, Vol. 23 No. 3, pp. 197-203.

Ekmekci, O., Hancock, A.B. and Swayze, S. (2012), "Teaching statistical research methods to graduate students: lessons learned from three different degree programs", International Journal of Teaching and Learning in Higher Education, Vol. 24 No. 2, pp. 272-279. 
Fisher, C. (2010), Researching and Writing a Dissertation: An Essential Guide for Business Students, $3^{\text {rd }}$ ed., Prentice Hall, Harlow.

Galliers, R.D. and Huang, J.C. (2012), "The teaching of qualitative research methods in information systems: an explorative study utilising learning theory", European Journal of Information Systems, Vol. 21 No. 2, pp. 119-134.

Garnett, J., Abraham, S. and Abraham, P. (2016), "Using work-based and work-applied learning to enhance the intellectual capital of organisations", Journal of Work-Applied Management, Vol. 8 No. 1, pp. 56-64.

Experiences and challenges of MBA students

Guest, G., Bunce, A. and Johnson, L. (2006), "How many interviews are enough? An experiment with data saturation and variability", Field Methods, Vol. 18 No. 1, pp. 59-82.

Harraway, J.A. and Barker, R.J. (2005), "Statistics in the workplace: a survey of use by recent graduates with higher degrees", Statistics Education Research Journal, Vol. 4 No. 2, pp. 43-58.

Howitt, D. and Cramer, D. (2008), Introduction to Research Methods in Psychology, 2nd ed., Prentice Hall, Harlow.

Johnson, C. and Spicer, D.P. (2006), “A case study of action learning in an MBA program”, Education + Training, Vol. 48 No. 1, pp. 39-54.

Kelliher, F. and Byrne, S. (2018), "The thinking behind the action (learning): reflections on the design and delivery of an executive management program", Journal of Work-Applied Management, Vol. 10 No. 1, pp. 35-49.

Kilburn, D., Nind, M. and Wiles, R. (2014), "Learning as Researchers and Teachers: the development of a pedagogical culture for social science research methods?", British Journal of Educational Studies, Vol. 62 No. 2, pp. 191-207.

Lewthwaite, S. and Nind, M. (2016), "Teaching research methods in the social sciences: expert perspectives on pedagogy and practice”, British Journal of Educational Studies, Vol. 64 No. 4, pp. 413-430.

Llamas, J.M.C. and Boza, A. (2011), "Teaching research methods for doctoral students in education: learning to enquire in the university", International Journal of Social Research Methodology, Vol. 14 No. 1, pp. 77-90.

Manroop, L. (2017), "A multiparadigm approach to job search scholarship”, Organizational Psychology Review, Vol. 7 No. 4, pp. 330-56.

Morse, J. (1994), "Designing funded qualitative research", in Denzin, N. and Lincoln, Y. (Eds), Handbook for Qualitative Research, Sage, Thousand Oaks, CA, pp. 220-235.

Mullins, M.H. (2017), "Actively teaching research methods with a process oriented guided inquiry learning approach”, Journal of Teaching in Social Work, Vol. 37 No. 4, pp. 309-321.

Nzekwe-Excel, C. (2012), "An exploratory study on the learning needs of foundation degree students", International Journal of Learning, Vol. 18 No. 6, pp. 199-214.

Nzekwe-Excel, C. (2014), "Enhancing students learning experience: study-techniques and learning development", International Journal of Learning in Higher Education, Vol. 20 No. 1, pp. 45-53.

Ransford, E. and Butler, G. (1982), "Teaching research methods in the social sciences”, Teaching Sociology, Vol. 9 No. 3, pp. 291-312.

Ronnie, L. (2017), "Dyadic processes in postgraduate education: insights from MBA student experiences", International Journal of Management in Education, Vol. 15 No. 3, pp. 513-519.

Rowe, L., MossMoore, D.N. and Perrin, D. (2017), "The challenges of managing degree apprentices in the workplace A manager's perspective", Journal of Work Applied Management, Vol. 9 No. 2, pp. 185-199.

Savage, M. and Burrows, R. (2007), "The coming crisis of empirical sociology”, Sociology, Vol. 41 No. 5, pp. 885-899. 
JWAM

14,1

62
Schaupp, L.C. and Vitullo, E.A. (2019), "Implementing experiential action learning in the MBA: use of an international consulting experience", International Journal of Educational Management, Vol. 34 No. 3, pp. 505-517.

Tashakkori, A. and Teddlie, C. (2003), "Issues and dilemmas in teaching research methods courses in social and behavioural sciences: US perspective", International Journal of Social Research Methodology, Vol. 6 No. 1, pp. 61-77.

Taylor, S.J. and Bogdan, R. (1984), Introduction to Qualitative Research Methods: The Search for Meanings, John Wiley \& Sons, New York.

Toledano-O'Farrill, R. (2017), "Professional application projects: work-based learning in the curriculum", Journal of Higher Education, Skills and Work-Based Learning, Vol. 7 No. 1, pp. 21-34.

Wall, T., Russell, J. and Moore, N. (2017a), "Positive emotion in workplace impact: the case of a workbased learning project utilising appreciative inquiry", Journal of Work-Applied Management, Vol. 9 No. 2, pp. 129-146.

Wall, T., Bellamy, L., Evans, V. and Hopkins, S. (2017b), "Revisiting impact in the context of workplace research: a review and possible directions", Journal of Work Applied Management, Vol. 9 No. 2, pp. 95-109.

Wiltshier, F. (2011), "Researching with NVivo", Forum: Qualitative Social Research, Vol. 12 No. 1, [online], available at: http://www.qualitative-research.net/index.php/fqs/article/view/1628/3146 (accessed 19 June 2019).

Winn, S. (1995), "Learning by doing: teaching research methods through student participation in a commissioned research project", Studies in Higher Education, Vol. 20 No. 2, pp. 203-214.

Zablotsky, D. (2001), "Why do I have to learn this if I'm not going to graduate school? Teaching research methods in a social psychology of aging course", Educational Gerontology, Vol. 27 No. 7, pp. 609-622.

\section{Corresponding author}

Chinny Nzekwe-Excel can be contacted at: nyerenoels@mail.com

For instructions on how to order reprints of this article, please visit our website:

www.emeraldgrouppublishing.com/licensing/reprints.htm

Or contact us for further details: permissions@emeraldinsight.com 